\title{
Evaluation of response from axitinib per Response Evaluation Criteria in Solid Tumors versus Choi criteria in previously treated patients with metastatic renal cell carcinoma
}

\author{
This article was published in the following Dove Press journal: \\ OncoTargets and Therapy \\ 12 May 2016 \\ Number of times this article has been viewed
}

\author{
Pierre I Karakiewicz' \\ Louise Nott ${ }^{2}$ \\ Abhishek Joshi ${ }^{3}$ \\ George Kannourakis ${ }^{4,5}$ \\ Jamal Tarazi ${ }^{6}$ \\ Mahmood Alam ${ }^{7}$ \\ 'Cancer Prognostics and Health \\ Outcomes Unit, University of \\ Montreal Health Center, Montreal, \\ QC, Canada; ${ }^{2}$ Department of \\ Haematology and Oncology, Royal \\ Hobart Hospital, Hobart, TAS, \\ ${ }^{3}$ Townsville Cancer Centre, Townsville \\ Hospital, James Cook University, \\ Townsville, QLD, ${ }^{4}$ Fiona Elsey Cancer \\ Research Institute, Ballarat, ${ }^{5}$ Ballarat \\ Oncology and Haematology Services, \\ Wendouree, VIC, Australia; ${ }^{6} \mathrm{Clinical}$ \\ Development, Pfizer Oncology, San \\ Diego, CA, USA; ${ }^{7}$ Regional Medical \\ Affairs, Pfizer Oncology, Asia Pacific \\ Region, West Ryde, NSW, Australia
}

Correspondence: Mahmood Alam Pfizer Oncology, Asia Pacific Region, 38-42 Wharf Road, West Ryde, NSW 21 I4, Australia

Tel +6I 298134615

Fax +6I 295057122

Email mahmood.alam2@pfizer.com
Background: Axitinib, a selective and potent tyrosine kinase inhibitor of vascular endothelial growth factor receptors, was available to patients from Canada and Australia, prior to regulatory approval of axitinib in these countries, for treatment of clear-cell metastatic renal cell carcinoma (mRCC) after failure of one prior systemic regimen.

Methods: This single-arm, open-label study of axitinib evaluated the efficacy, safety, and quality of life (QoL) in patients with $\mathrm{mRCC}$ whose disease progressed after one prior systemic first-line regimen. Primary objective was objective response rate evaluated per Response Evaluation Criteria in Solid Tumors (RECIST) and Choi criteria. Progression-free survival, overall survival, safety, and QoL were secondary end points. Due to the small study size, analyses comprised of descriptive statistics.

Results: Fifteen patients were recruited, five from Canada and ten from Australia, over a limited recruitment period. Thirteen patients received sunitinib as prior therapy. All patients had clear-cell carcinoma, eleven had prior nephrectomy. Liver, lung, and lymph nodes were the most frequent sites of metastases; one patient had brain metastasis. Median time on axitinib was 118.0 days (range: 3.5-645.0 days); estimated survival probability at 12 months was $57.8 \%$. Two (13.3\%) patients had objective responses per RECIST versus nine $(60.0 \%)$ per Choi criteria. Six patients had progressive disease based on RECIST versus three per Choi criteria. Nine $(60.0 \%)$ events of progression or death occurred by the end of study, and three patients continued to receive the study drug. Fatigue (33\%) and diarrhea (20\%) were the most common grade $\geq 3$ all-causality, treatment-emergent adverse events. The mean change in European Quality of Life - 5 Dimensions score from baseline to end of treatment was -0.0837 .

Conclusion: The small number of patients and lack of a comparator arm limit the ability to draw definitive conclusions; however, safety and efficacy profiles of axitinib were consistent with reports from previous studies in patients with $\mathrm{mRCC}$, and patients generally maintained QoL. The sizeable difference observed in objective response rate by RECIST versus Choi criteria merits further research.

Keywords: RECIST, objective response rate, metastatic, vascular endothelial growth factor receptor inhibitor

\section{Introduction}

Kidney cancer accounts for $2 \%-3 \%$ of all adult cancers and was newly diagnosed in 337,860 people in 2012 worldwide, resulting in $>143,000$ deaths. ${ }^{1}$ Approximately 
$90 \%$ of kidney cancers are renal cell carcinoma (RCC) and $85 \%$ of those are clear-cell tumors. ${ }^{2}$ Treatment of metastatic RCC (mRCC) has been transformed in the last decade with the development of agents that target tumor angiogenesis by inhibiting either the vascular endothelial growth factor (VEGF) pathway ${ }^{3-13}$ or the mammalian target of rapamycin pathway. ${ }^{14,15}$

Axitinib (Inlyta ${ }^{\circledR}$; Pfizer Inc, New York, NY, USA ${ }^{16}$ ) is an oral, potent, and selective second-generation inhibitor of VEGF receptors 1,2 , and $3 .{ }^{17}$ In the global Phase III AXIS trial, axitinib demonstrated superior efficacy over sorafenib in patients with $\mathrm{mRCC}$ after failure of one prior systemic therapy. ${ }^{18}$ Median progression-free survival (PFS) was 6.7 months (95\% CI: 6.3-8.6) with axitinib compared with 4.7 months (95\% CI: 4.6-5.6) with the active comparator, sorafenib (hazard ratio, 0.665; 95\% CI: 0.544-0.812, onesided $P<0.0001)$. Axitinib is approved in 66 countries, including the USA, ${ }^{16}$ European Union, Japan, and South Korea, for treatment of previously treated patients with advanced RCC.

Tumor response to treatment has been traditionally evaluated using Response Evaluation Criteria in Solid Tumors (RECIST), which monitors changes in tumor size. ${ }^{19}$ With the introduction of targeted therapies, the use of RECIST criteria has often been questioned. It is based on tumor size measurements, whereas many targeted agents do not necessarily change tumor size but decrease tumor vascularization and cause necrosis; evaluation based on only size can lead to underestimation of tumor response to treatment. The Choi criteria were therefore introduced. ${ }^{20}$ These criteria evaluate changes in tumor size and density and were found to be effective in assessing early response to treatment in gastrointestinal stromal tumors (GISTs), ${ }^{20-23}$ hepatocellular carcinoma, ${ }^{24,25}$ and high-risk soft tissue sarcoma. ${ }^{26}$ Choi criteria were also valuable in early detection of response to sunitinib in patients with mRCC. ${ }^{27}$

We report results from a compassionate use study that provided access to axitinib treatment to Canadian and Australian patients with $\mathrm{mRCC}$ whose disease progressed after one prior systemic therapy. Axitinib became commercially available in Canada and Australia while the study was ongoing. The primary objective of this study was to determine overall (complete + partial) objective response rate (ORR) per RECIST criteria, Version 1.1. Choi criteria were also used to assess response, and the results were compared with RECIST. Secondary objectives included assessment of PFS, overall survival (OS), safety, and quality of life (QoL) measures.

\section{Methods}

\section{Patients}

Patients included in this study were men and nonpregnant, nonlactating women aged 18 years or older with histologically or cytologically confirmed mRCC with a component of clear-cell subtype who failed a prior single line of therapy with either a single agent or a combination of any of the following agents: interleukin-2, interferon, bevacizumab, sunitinib, pazopanib, tivozanib, temsirolimus, or everolimus. Patients had evidence of disease, with at least one measurable lesion as per RECIST Version 1.1; Eastern Cooperative Oncology Group performance status (ECOG PS) 0 or 1; adequate renal, hepatic, and hematologic organ function; life expectancy of at least 12 weeks; at least 2 weeks since the end of prior systemic treatment ( 4 weeks for bevacizumab plus interferon- $\alpha$ ), radiotherapy, or surgical procedure; and no uncontrolled hypertension $(>140 / 90 \mathrm{mmHg})$, based on two baseline blood pressure $(\mathrm{BP})$ readings taken at least 1 hour apart.

Key exclusion criteria included having major bowelpenetrating surgery within $<4$ weeks of starting the study treatment; active peptic ulcer disease in the past 6 months or active gastrointestinal bleeding in the past 3 months; current or anticipated use of potent inhibitors of cytokine P450 (CYP) 3A4/5 or inducers of CYP3A4/5 or CYP1A2; anticoagulant therapy with oral vitamin $\mathrm{K}$ antagonists; evidence of symptomatic or untreated brain metastases, spinal cord compression, carcinomatous meningitis, or active seizure disorder; myocardial infarction, uncontrolled angina, coronary/peripheral artery bypass graft, symptomatic congestive heart failure, cerebrovascular accident or transient ischemic attack, or aneurism at risk of rupture within 12 months prior to study drug administration; or history of a malignancy other than RCC.

\section{Study design}

This was a single-arm, open-label, multicenter study of axitinib in patients with $\mathrm{mRCC}$ whose disease progressed after one prior systemic first-line regimen containing single or combination therapy with a cytokine, VEGF, or mammalian target of rapamycin inhibitor or those who discontinued due to prohibitive toxicity. The study was conducted in two countries: Australia (three centers) and Canada (one center).

The study protocol, amendments, and informed consent forms were reviewed and approved by the institutional review board or independent ethics committee at each study center (Table S1). The study was conducted in accordance with the protocol, International Conference on Harmonization Good 
Clinical Practice guidelines, and applicable local regulatory requirements and laws. Informed consent was obtained from each patient prior to study initiation. This trial is registered on ClinicalTrials.gov, identifier NCT01473043.

\section{Treatment}

Axitinib was taken orally with or without food at starting dose of $5 \mathrm{mg}$ twice daily on a continuous basis, as established previously. ${ }^{18}$ Dose titration was based on BP response and toxicity experienced as previously described. ${ }^{18}$ Study treatment was administered in cycles of 4 weeks in duration.

\section{Assessments}

Baseline tumor assessments included computed tomography/ magnetic resonance imaging scans of the brain, chest, abdomen, pelvis, and bone. Computed tomography/magnetic resonance imaging scans (except brain) were repeated every 8 weeks. Data on best response, PFS, and time to progression were collected according to RECIST Version 1.1. ${ }^{28}$ Bone or brain scans were only required if clinically indicated. Responses were evaluated by the respective radiologist at each site. Tumor response was also assessed based on Choi criteria using the same target lesions used for baseline estimation as per RECIST. The radiologists in each center received training in the interpretation of Choi criteria. Density measurements were performed by drawing a perimeter around the target lesion and documenting the pixel value in Hounsfield Units. After measuring the densities of all identified target lesions, a total sum value of densities was recorded at baseline and was used as a reference point to assess response on follow-up measurements. Assessment of tumor response per Choi criteria was as described previously, ${ }^{20}$ where complete response is based on size criteria only and partial response is based on a decrease $\geq 15 \%$ in density of the sum value from baseline (Table 1).
Per protocol, patients were to be followed-up for survival every 3 months for up to 2 years after last patient/first visit; however, follow-up was only completed until the end date of the study, March 12, 2014.

Safety was assessed in all patients by adverse events (AEs) graded according to National Cancer Institute Common Terminology Criteria for Adverse Events Version 4.0. All observed or volunteered AEs (serious and nonserious), their severity, and relationship to the investigational drug were reported throughout the study. Physical examination, including the assessment of all body systems (including neurologic assessment), the measurement of body weight, height, pulse, and temperature, and the assessment of ECOG PS was performed at baseline, on day 1 (if $>7$ days since baseline), every 4 weeks, and at end of study treatment. A single 12-lead electrocardiogram was performed on all patients at screening. Additional electrocardiograms were performed as clinically indicated.

BP was monitored at each clinic visit and at least twice daily at home by the patient prior to taking each dose of axitinib. Patients were instructed to inform their doctor immediately if systolic BP was $>150 \mathrm{mmHg}$, diastolic $\mathrm{BP}>100 \mathrm{mmHg}$, or if symptoms perceived to be related to elevated BP (eg, headache and visual disturbance) developed. Laboratory tests for hematology, chemistry, and biochemistry were performed at baseline, day 1 (if $>7$ days since baseline), every 4 weeks, and end of study treatment. Thyroid function tests (free triiodothyronine, free thyroxine, and thyroid-stimulating hormone) were performed at baseline (cycle 1 day 1 , predose), cycle 1 day 15 , cycle 2 day 1 , cycle 3 day 1 , cycle 4 day 1 , cycle 5 day 1 , and beginning with cycle 6 day 1 , every 8 weeks thereafter.

Patient-reported outcomes were assessed using the European Quality of Life - 5 Dimensions (EQ-5D) ${ }^{24}$ questionnaire administered on cycle 1 day 1 before dosing and

Table I Comparison of Choi and RECIST I.I criteria

\begin{tabular}{|c|c|c|}
\hline \multirow[t]{2}{*}{ Response } & \multicolumn{2}{|l|}{ Definition } \\
\hline & Choi criteria ${ }^{20}$ & RECIST I. $\left.\right|^{28}$ \\
\hline Complete response & $\begin{array}{l}\text { Disappearance of all lesions } \\
\text { No new lesions }\end{array}$ & $\begin{array}{l}\text { Disappearance of all target lesions, all nodal } \\
\text { lesions have short axis }<10 \mathrm{~mm}\end{array}$ \\
\hline Partial response & $\begin{array}{l}\text { A decrease in size } \geq 10 \% \text { or a decrease in tumor } \\
\text { attenuation }(\mathrm{HU}) \geq 15 \% \text { on } \mathrm{CT} \\
\text { No new lesions } \\
\text { No obvious progression of nonmeasurable disease }\end{array}$ & $\begin{array}{l}\geq 30 \% \text { decrease in the sum of diameters from } \\
\text { baseline sum diameters }\end{array}$ \\
\hline Progressive disease & $\begin{array}{l}\text { An increase in tumor size } \geq 10 \% \text { and does not } \\
\text { meet criteria of PR by tumor attenuation on } C T \\
\text { New lesions }\end{array}$ & $\begin{array}{l}\geq 20 \% \text { increase in the smallest sum of diameters } \\
\text { as reference with an absolute increase of } \geq 5 \mathrm{~mm}\end{array}$ \\
\hline Stable disease & Does not meet the above criteria & Does not meet the above criteria \\
\hline
\end{tabular}

Abbreviations: RECIST, Response Evaluation Criteria in Solid Tumors; CT, computed tomography; PR, partial response. 
before any other clinical assessments, then every 4 weeks while on study, at end of study treatment/withdrawal, and at follow-up (28 days after last dose). EQ-5D summary results were derived by combining one level from each of the five EQ-5D dimensions (mobility, self-care, usual activities, pain/discomfort, and anxiety/depression) and converting to a single summary index. Possible EQ-5D scores range from -0.594 to 1 , with low scores representing a higher level of dysfunction. For the EuroQol Visual Analogue Scale, patients rated their overall health status from 0 (worst imaginable) to 100 (best imaginable).

\section{Statistical analyses}

The primary efficacy end point was ORR as assessed by the investigator. ORR was defined as the proportion of patients with confirmed complete response or confirmed partial response according to RECIST.${ }^{19}$ Confirmed responses were those that persisted on repeat-imaging study at least 4 weeks after the initial documentation of response. Patients who did not have on-study radiographic tumor reevaluation or who died, progressed, or discontinued for any reason prior to reaching a complete or partial response were counted as nonresponders in the assessment of ORR. A patient who initially met the criteria for a partial response and then subsequently confirmed as a complete responder was assigned a best response of complete response. Response status was also defined and summarized based on Choi criteria in a similar manner as for the response status defined by RECIST. ${ }^{20}$

Secondary end points included PFS, defined as the time from date of first dose of study drug to first documentation of objective tumor progression or death. Clinical benefit rate was defined as the proportion of patients with confirmed complete response, confirmed partial response, or stable disease for $\geq 8$ weeks to treatment failure. OS was defined as the time from date of first dose of study drug to first documentation of death due to any cause.

Efficacy, safety, and patient-reported outcomes were analyzed in the full analysis set (ie, all enrolled patients who received at least one dose of axitinib during the study period). This study was noncomparative, and no inferential statistical analyses were planned. Analyses consisted of descriptive statistics and corresponding 95\% two-sided CIs when appropriate. PFS and OS were summarized using KaplanMeier method and displayed graphically. The median event time was provided for PFS and OS. All data summaries and tabulations were prepared by using $\mathrm{SAS}^{\circledR}$ Version 9.2 (SAS Institute Inc., Cary, NC, USA).

\section{Results}

\section{Patients and treatment}

Between March 1, 2012, and March 12, 2014, 15 previously treated patients with $\mathrm{mRCC}$ (five from one center in Canada and ten from three centers in Australia) were enrolled in the study and included in the full analysis set. Demographic and baseline characteristics are presented in Table 2. The mean age of patients was 55.1 years, and $12(80.0 \%)$ patients were $<65$ years of age. Seven $(46.7 \%)$ patients had ECOG PS 0 and eight (53.3\%) had ECOG PS 1. Eleven (73.3\%) patients had previous surgery for nephrectomy. Prior treatment regimens included sunitinib-containing $(n=13)$, pazopanib-containing $(\mathrm{n}=1)$, and tivozanib-containing $(n=1)$ therapies. Median time on axitinib was 118.0 days

Table 2 Patient demographics and baseline characteristics

\begin{tabular}{|c|c|}
\hline Characteristic & $\begin{array}{l}\text { Axitinib } \\
(\mathrm{N}=15)\end{array}$ \\
\hline \multicolumn{2}{|l|}{ Age, years } \\
\hline Mean (SD) & $55.1(9.86)$ \\
\hline Median (range) & $54.0(33-71)$ \\
\hline \multicolumn{2}{|l|}{ Age, years } \\
\hline$<65$ & $12(80.0)$ \\
\hline$\geq 65$ & $3(20.0)$ \\
\hline \multicolumn{2}{|l|}{ Sex } \\
\hline Male & II (73.3) \\
\hline Female & $4(26.7)$ \\
\hline \multicolumn{2}{|l|}{ Race } \\
\hline White & $15(100)$ \\
\hline \multicolumn{2}{|l|}{ ECOG PS } \\
\hline 0 & $7(46.7)$ \\
\hline I & $8(53.3)$ \\
\hline \multicolumn{2}{|c|}{ MSKCC risk group (no of risk factors) ${ }^{b}$} \\
\hline Favorable $(0)$ & $4(26.7)$ \\
\hline Intermediate (I) & $6(40.0)$ \\
\hline Poor (2-3) & $5(33.3)$ \\
\hline \multicolumn{2}{|l|}{ Current stage } \\
\hline Stage III & $\mathrm{I}(6.7)$ \\
\hline Stage IV & $14(93.3)$ \\
\hline \multicolumn{2}{|l|}{ Prior nephrectomy } \\
\hline No & $4(26.7)$ \\
\hline Yes & II (73.3) \\
\hline \multicolumn{2}{|l|}{ Metastatic site } \\
\hline Bone & $4(26.7)$ \\
\hline Brain & I (6.7) \\
\hline Liver & $8(53.3)$ \\
\hline Lung & $7(46.7)$ \\
\hline Lymph node & $15(100.0)$ \\
\hline Other & $12(80.0)$ \\
\hline
\end{tabular}

Notes: Data are $\mathrm{n}$ (\%) unless noted. ${ }^{\mathrm{a} E C O G}$ PS from case report forms; last measure taken before dosing on or before randomization date. ${ }^{\mathrm{B}} \mathrm{MSKCC}$ risk groups were classified using the following three risk factors: low serum hemoglobin (less than the lower limit of normal), high corrected serum calcium $(>10 \mathrm{mg} / \mathrm{dL})$, and ECOG PS (0 versus I). ${ }^{38}$

Abbreviations: ECOG PS, Eastern Cooperative Oncology Group performance status; MSKCC, Memorial Sloan-Kettering Cancer Center. 
Table 3 Best response according to RECIST and Choi criteria following treatment with axitinib: full analysis set

\begin{tabular}{|c|c|c|}
\hline \multirow[t]{2}{*}{ Objective tumor response } & \multicolumn{2}{|l|}{ n (\%) } \\
\hline & RECIST I.I & Choi \\
\hline Patients with baseline assessment & $15(100)$ & $15(100)$ \\
\hline $\begin{array}{l}\text { Patients with measurable disease } \\
\text { at baseline }\end{array}$ & $15(100)$ & $15(100)$ \\
\hline \multicolumn{3}{|l|}{ Best overall response } \\
\hline Complete response & 0 & 0 \\
\hline Partial response & $2(13.3)$ & $9(60.0)$ \\
\hline Stable disease & $4(26.7)$ & 0 \\
\hline Progressive disease & $6(40.0)$ & $3(20.0)$ \\
\hline Not assessed & I (6.7) & I (6.7) \\
\hline Early death & 0 & I (6.7) \\
\hline Indeterminate & $2(13.3)$ & $\mathrm{I}(6.7)$ \\
\hline $\begin{array}{l}\text { Overall confirmed ORR (complete } \\
\text { response + partial response) }\end{array}$ & $2(13.3)$ & $9(60.0)$ \\
\hline $95 \%$ exact $\mathrm{Cl}^{\mathrm{a}}$ & $1.7 \%-40.5 \%$ & $16.3 \%-67.7 \%$ \\
\hline
\end{tabular}

Note: a Using exact method based on binomial distribution.

Abbreviations: RECIST, Response Evaluation Criteria in Solid Tumors; ORR, overall response rate; $\mathrm{Cl}$, confidence interval.

(range: 3.5-645.0 days). The median daily dose was $13.5 \mathrm{mg}$ (range: $4.33-19.27 \mathrm{mg}$ ). Thirteen $(86.7 \%$ ) patients had their daily dose increased $>10 \mathrm{mg}$ for at least two consecutive doses at any time during the study. Five (33.3\%) patients had their daily dose reduced $<10 \mathrm{mg}$ for at least two consecutive doses at any time during the study.

\section{Efficacy}

Two (13.3\%) patients had a confirmed partial response as assessed by the investigator using RECIST compared with nine $(60.0 \%)$ patients when Choi criteria were applied (Table 3). Of the nine patients who had partial response per
Choi, RECIST criteria categorized two with partial response, four with stable disease, one with indeterminate response, and two with progressive disease. No complete responses were reported with either criteria, four patients had stable disease and six patients had progressive disease per RECIST, whereas no patient had stable disease and three patients had progressive disease per Choi criteria (Table 3). Six (40.0\%) patients had a clinical benefit according to RECIST. Nine $(60 \%)$ events of progression or death were reported at study end and three patients continued on study drug. A median PFS of 2.5 months (95\% CI: 1.7 - not estimable; Figure 1) was observed. The estimated survival probability at 12 months was 57.8\% (95\% CI: 29.0-78.4). Eight patients were alive at the time of study closure and were not followed-up further for OS, thus limiting further interpretation of OS data.

\section{Safety}

Treatment-emergent AEs (TEAEs) are shown in Table 4. Overall, 15 (100\%) patients experienced a total of 176 TEAEs. Six $(40.0 \%)$ patients experienced treatment-emergent serious AEs; four (26.7\%) experienced treatment-emergent, treatment-related serious AEs. Three (20.0\%) patients discontinued treatment due to TEAEs. The most common all-grade, all-causality TEAEs ( $\%$ patients) were fatigue (73.3\%), diarrhea $(60.0 \%)$, and decreased appetite $(53.3 \%)$. The most common grade $\geq 3$ all-causality TEAEs were fatigue $(33.3 \%)$ and diarrhea $(20.0 \%)$. Seven $(46.7 \%)$ patients died during the study: one $(6.7 \%)$ patient during treatment and six (40.0\%) patients during follow-up. The cause of death in all cases was $\mathrm{mRCC}$ related. No patients had

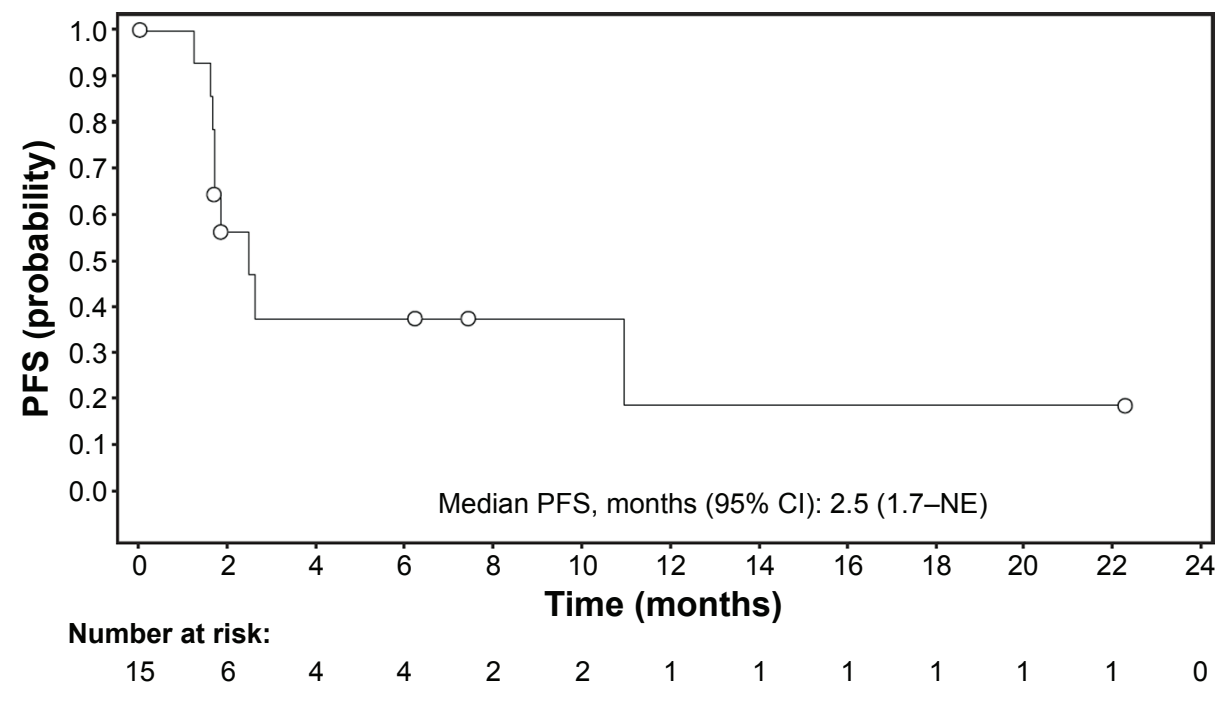

Figure I Kaplan-Meier curve estimate for progression-free survival (derived investigator's assessment): full analysis set. Abbreviations: NE, not estimable; PFS, progression-free survival; $\mathrm{Cl}$, confidence interval. 
Table 4 Treatment-emergent, all-causality adverse events experienced by $>10 \%$ of patients

\begin{tabular}{|c|c|c|}
\hline \multirow[t]{2}{*}{ MedDRA preferred term } & \multicolumn{2}{|c|}{ Axitinib, $N=15, n(\%)$} \\
\hline & All grades & Grade $\geq 3$ \\
\hline Fatigue & II (73.3) & $5(33.3)$ \\
\hline Diarrhea & $9(60.0)$ & $3(20.0)$ \\
\hline Decreased appetite & $8(53.3)$ & $2(13.3)$ \\
\hline Hypertension & $6(40.0)$ & $2(13.3)$ \\
\hline Nausea & $5(33.3)$ & I (6.7) \\
\hline Weight decrease & $5(33.3)$ & I (6.7) \\
\hline Arthralgia & $4(26.7)$ & 0 \\
\hline Back pain & $4(26.7)$ & I (6.7) \\
\hline PPE & $4(26.7)$ & I (6.7) \\
\hline Hyperthyroidism & $3(20.0)$ & 0 \\
\hline Muscle spasms & $3(20.0)$ & I (6.7) \\
\hline Dysphonia & $3(20.0)$ & 0 \\
\hline Proteinuria & $2(13.3)$ & $2(13.3)$ \\
\hline Dysphagia & $2(13.3)$ & I (6.7) \\
\hline Vomiting & $2(13.3)$ & 0 \\
\hline Mucosal inflammation & $2(13.3)$ & 0 \\
\hline Upper respiratory tract infection & $2(13.3)$ & 0 \\
\hline Muscular weakness & $2(13.3)$ & 0 \\
\hline Dizziness & $2(13.3)$ & 0 \\
\hline Headache & $2(13.3)$ & 0 \\
\hline Rash & $2(13.3)$ & 0 \\
\hline
\end{tabular}

Abbreviations: MedDRA, Medical Dictionary for Regulatory Activities v16.I coding dictionary; PPE, palmar-plantar erythrodysesthesia.

arterial thromboembolic events, gastrointestinal perforation, hemorrhage, hepatic disorders, or venous thrombolic events. No patients had AEs related to hematology parameters. One (6.7\%) patient had an $\mathrm{AE}$ related to chemistry parameters (grade 2 hypercalcemia) and two (13.3\%) had AEs related to urinalysis parameters (grade 3 proteinuria). Two (13.3\%) patients had grade 1 hyperthyroidism, one (6.7\%) had grade 2 hyperthyroidism, one $(6.7 \%)$ had grade 1 blood thyroidstimulating hormone increase, and one (6.7\%) patient had grade 1 abnormal thyroid function test.

\section{Patient-reported outcomes}

Mean EQ-5D score at baseline was 0.7947 , and mean change from baseline to end of treatment was -0.0837 . Mean EuroQol Visual Analogue Scale score at baseline was 73.3, and mean change from baseline to end of treatment was -6.5 .

\section{Discussion}

Although limited by the small number of patients and the lack of a reference arm, the efficacy results observed in previously treated Canadian and Australian patients with mRCC treated with axitinib in the current study are consistent with previous studies ${ }^{18,29-31}$ and provide further support for the use of axitinib in patients with $\mathrm{mRCC}$ whose disease progressed after one prior systemic therapy.
Response rate following axitinib treatment was higher using Choi criteria than RECIST criteria. These results are consistent with previous studies in patients with metastatic GIST, where more patients were responders by Choi than by RECIST criteria, respectively, after treatment with imatinib $(84 \% \text { versus } 48 \%)^{21}$ or sunitinib (31\% versus $\left.2 \%\right){ }^{32}$ Studies in patients with hepatocellular carcinoma also showed that more patients met Choi response criteria than RECIST, respectively, after treatment with transarterial radioembolization $(78 \% \text { versus } 22 \%)^{25}$ or sorafenib $(38 \%$ versus $15 \%){ }^{33}$ However, there are contradicting results regarding the ability of Choi criteria to better predict therapeutic benefit than RECIST. One study in GIST showed that responders by Choi criteria were correlated with significantly longer time to progression and disease-specific survival than nonresponders, whereas by RECIST, responders were not significantly correlated with time to progression or diseasespecific survival compared with nonresponders..$^{21}$ Similarly, a study in hepatocellular carcinoma showed that responders according to Choi criteria had a significantly longer time to progression (median: 280 days versus 166 days) and OS (median: 442 days versus 247 days) than nonresponders, respectively, whereas based on RECIST, responders did not have improved time to progression or OS compared with nonresponders..$^{25}$ However, other studies in GIST and in highgrade soft-tissue sarcomas demonstrated that although more patients had response based on Choi criteria compared with RECIST, the absence of progression (partial response plus stable disease) was the most important predictive marker of therapeutic benefit regardless of response criteria used. ${ }^{26,32}$

Choi criteria have not been studied widely in the context of mRCC and ours is the first study of axitinib administered as second-line treatment in patients with $\mathrm{mRCC}$ whose tumor responses were evaluated using both RECIST 1.1 and Choi criteria. A previous study in patients with $\mathrm{mRCC}$ treated with sunitinib showed that at first evaluation, more patients experienced tumor response based on Choi versus RECIST criteria, respectively (partial response: $n=36$ versus 7 ; stable disease: $\mathrm{n}=6$ versus 38 ; and progressive disease: $\mathrm{n}=13$ versus 10$).{ }^{27}$ Furthermore, at first evaluation, response by Choi criteria was a significantly better predictor of PFS and OS than response by RECIST. However, when best response (partial response plus stable disease $\geq 12$ weeks) was taken into account, Choi criteria were not superior to RECIST criteria in predicting PFS or OS in patients with $\mathrm{mRCC}$ treated with sunitinib. ${ }^{27}$ Results from our study, albeit small, are in line with most of the published data. As predicted, there were a higher number of patients with partial response when Choi criteria were applied. This is understandable, as the decreased 
vascularity or necrotic tumor cells within the target lesion may not immediately result in a change in size; however, they would have a different density that can be accurately checked if Choi criteria are used. In some cases, this may mean an underevaluation of clinical benefit and a premature discontinuation of treatment for the patient.

Maintaining the highest possible QoL is another goal for the treatment of mRCC. Patients treated with axitinib were generally able to maintain QoL while on treatment, before their disease progressed. No new safety concerns were identified, and the most commonly reported AEs (fatigue, diarrhea, and decreased appetite) were consistent with those reported previously in patients with $\mathrm{mRCC}$ treated with axitinib ${ }^{18,29,30,34}$ or other inhibitors of the VEGF pathway. ${ }^{6,35-37}$

The results from this study should be viewed with respect to its limitations. This was a single-arm study with a small number of patients; therefore, data observed in this study had to be compared with efficacy and safety profiles of axitinib observed in previous clinical studies. Also, tumor response was assessed by the study radiologists and not by an independent review committee. In addition, the study ended prematurely, and patients were not followed-up for survival for up to 2 years, as planned, but only until the end date of the study.

\section{Conclusion}

This study provided early access to axitinib for Australian and Canadian patients who failed one prior therapy for mRCC. The small number of patients and the lack of a reference arm in this study limit the ability to draw definitive conclusions. However, the safety and efficacy profiles of axitinib in this study were consistent with those seen in previous studies in patients with mRCC and generally enabled patients to maintain QoL. The sizeable difference observed in ORR between RECIST and Choi criteria (13\% versus $60 \%$, respectively) indicates that the use of Choi criteria to assess tumor response in patients with $\mathrm{mRCC}$ merits further research in a larger, prospective, and randomized study.

\section{Acknowledgments}

The study was sponsored by Pfizer Inc. Medical writing support was provided by Vardit Dror, $\mathrm{PhD}$, of Engage Scientific Solutions and was funded by Pfizer Inc.

\section{Disclosure}

Mahmood Alam and Jamal Tarazi are full time employees of Pfizer Inc. and declare stock options from Pfizer Inc. Pierre I Karakiewicz, Louise Nott, Abhishek Joshi, and George Kannourakis report no conflicts of interest in this work.

\section{References}

1. International Agency for Research on Cancer [webpage on the Internet]. GLOBOCAN 2012 v1.0, Cancer Incidence and Mortality Worldwide: IARC CancerBase No. 11 [Internet]. Lyon, France: International Agency for Research on Cancer; 2013. Available from: http://globocan. iarc.fr. Accessed March 11, 2014.

2. National Comprehensive Cancer Network [webpage on the Internet]. NCCN Clinical Practice Guidelines in Oncology. Kidney Cancer. Version 1.2013 [Internet]; 2013. Available from: http://www.nccn.org/ professionals/physician_gls/f_guidelines_nojava.asp\#site. Accessed March 10, 2014.

3. Akaza H, Tsukamoto T, Murai M, Nakajima K, Naito S. Phase II study to investigate the efficacy, safety, and pharmacokinetics of sorafenib in Japanese patients with advanced renal cell carcinoma. Jpn J Clin Oncol. 2007;37(10):755-762.

4. Kim HS, Hong MH, Kim K, et al. Sunitinib for Asian patients with advanced renal cell carcinoma: a comparable efficacy with different toxicity profiles. Oncology. 2011;80(5-6):395-405.

5. Motzer RJ, Hutson TE, Cella D, et al. Pazopanib versus sunitinib in metastatic renal-cell carcinoma. $N$ Engl J Med. 2013;369(8):722-731.

6. Sternberg CN, Davis ID, Mardiak J, et al. Pazopanib in locally advanced or metastatic renal cell carcinoma: results of a randomized phase III trial. J Clin Oncol. 2010;28(6):1061-1068.

7. Sternberg CN, Hawkins RE, Wagstaff J, et al. A randomised, doubleblind phase III study of pazopanib in patients with advanced and/or metastatic renal cell carcinoma: final overall survival results and safety update. Eur J Cancer. 2013;49(6):1287-1296.

8. Tanigawa G, Kawashima A, Yamaguchi S, et al; Osaka Renal Cell Carcinoma Clinical Study Collaboration. Clinical outcome and prognostic factors of sorafenib in Japanese patients with advanced renal cell carcinoma in general clinical practice. Jpn J Clin Oncol. 2011;41(11): $1265-1270$

9. Tomita Y, Shinohara N, Yuasa T, et al. Overall survival and updated results from a phase II study of sunitinib in Japanese patients with metastatic renal cell carcinoma. Jpn J Clin Oncol. 2010;40(12):1166-1172.

10. Uemura H, Shinohara N, Yuasa T, et al. A phase II study of sunitinib in Japanese patients with metastatic renal cell carcinoma: insights into the treatment, efficacy and safety. Jpn J Clin Oncol. 2010;40(3): 194-202.

11. Yang L, Shi L, Fu Q, Xiong H, Zhang M, Yu S. Efficacy and safety of sorafenib in advanced renal cell carcinoma patients: results from a long-term study. Oncol Lett. 2012;3(4):935-939.

12. Yoo C, Kim JE, Lee JL, et al. The efficacy and safety of sunitinib in Korean patients with advanced renal cell carcinoma: high incidence of toxicity leads to frequent dose reduction. Jpn J Clin Oncol. 2010;40(10): 980-985.

13. Zhang H, Dong B, Lu JJ, et al. Efficacy of sorafenib on metastatic renal cell carcinoma in Asian patients: results from a multicenter study. BMC Cancer. 2009;9:249.

14. Guo J, Huang Y, Zhang X, et al. Safety and efficacy of everolimus in Chinese patients with metastatic renal cell carcinoma resistant to vascular endothelial growth factor receptor-tyrosine kinase inhibitor therapy: an open-label phase 1b study. BMC Cancer. 2013;13:136.

15. Sun Y, Rha S, Lee SH, et al. Phase II study of the safety and efficacy of temsirolimus in East Asian patients with advanced renal cell carcinoma. Jpn J Clin Oncol. 2012;42(9):836-844.

16. Inlyta ${ }^{\circledR}$ (axitinib) tablet, film coated [prescribing information]. New York: Pfizer Inc; 2012

17. Hu-Lowe DD, Zou HY, Grazzini ML, et al. Nonclinical antiangiogenesis and antitumor activities of axitinib (AG-013736), an oral, potent, and selective inhibitor of vascular endothelial growth factor receptor tyrosine kinases 1, 2, 3. Clin Cancer Res. 2008;14(22):7272-7283.

18. Rini BI, Escudier B, Tomczak P, et al. Comparative effectiveness of axitinib versus sorafenib in advanced renal cell carcinoma (AXIS): a randomised phase 3 trial. Lancet. 2011;378(9807):1931-1939.

19. Therasse P, Arbuck SG, Eisenhauer EA, et al. New guidelines to evaluate the response to treatment in solid tumors. J Natl Cancer Inst. 2000 92(3):205-216. 
20. Choi H, Charnsangavej C, Faria SC, et al. Correlation of computed tomography and positron emission tomography in patients with metastatic gastrointestinal stromal tumor treated at a single institution with imatinib mesylate: proposal of new computed tomography response criteria. J Clin Oncol. 2007;25(13):1753-1759.

21. Benjamin RS, Choi H, Macapinlac HA, et al. We should desist using RECIST, at least in GIST. J Clin Oncol. 2007;25(13):1760-1764.

22. Choi H. Response evaluation of gastrointestinal stromal tumors. Oncologist. 2008;13(Suppl 2):4-7.

23. Choi H, Charnsangavej $\mathrm{C}$, de Castro Faria S, et al. CT evaluation of the response of gastrointestinal stromal tumors after imatinib mesylate treatment: a quantitative analysis correlated with FDG PET findings. AJR Am J Roentgenol. 2004;183(6):1619-1628.

24. Kind P. The EuroQol instrument: an index of health-related quality of life. In: Spilker B, editor. Quality of Life and Pharmacoeconomics in Clinical Trials. 2nd ed. Philadelphia: Lippincott-Raven; 1996: 191-201.

25. Weng Z, Ertle J, Zheng S, et al. Choi criteria are superior in evaluating tumor response in patients treated with transarterial radioembolization for hepatocellular carcinoma. Oncol Lett. 2013;6(6):1707-1712.

26. Stacchiotti S, Verderio P, Messina A, et al. Tumor response assessment by modified Choi criteria in localized high-risk soft tissue sarcoma treated with chemotherapy. Cancer. 2012;118(23):5857-5866.

27. van der Veldt AA, Meijerink MR, van den Eertwegh AJ, Haanen JB, Boven E. Choi response criteria for early prediction of clinical outcome in patients with metastatic renal cell cancer treated with sunitinib. Br J Cancer. 2010;102(5):803-809.

28. Eisenhauer EA, Therasse P, Bogaerts J, et al. New response evaluation criteria in solid tumours: revised RECIST guideline (version 1.1). Eur J Cancer. 2009;45(2):228-247.

29. Rixe O, Bukowski RM, Michaelson MD, et al. Axitinib treatment in patients with cytokine-refractory metastatic renal-cell cancer: a phase II study. Lancet Oncol. 2007;8(11):975-984.
30. Ueda T, Uemura H, Tomita Y, et al. Efficacy and safety of axitinib versus sorafenib in metastatic renal cell carcinoma: subgroup analysis of Japanese patients from the global randomized phase 3 AXIS trial. Jpn J Clin Oncol. 2013;43(6):616-628.

31. Qin S, Bi F, Jin J, et al. Axitinib versus sorafenib as second-line therapy in Asian patients with metastatic renal cell carcinoma (mRCC): results from a registrational study. J Clin Oncol. 2012;30(18 Suppl):LBA4537.

32. Dudeck O, Zeile M, Reichardt P, Pink D. Comparison of RECIST and Choi criteria for computed tomographic response evaluation in patients with advanced gastrointestinal stromal tumor treated with sunitinib. Ann Oncol. 2011;22(8):1828-1833.

33. McCarthy F, Crusz S, Gobindpuri A, et al. The role of Choi criteria in assessing response to tyrosine kinase inhibitors (TKIs) in patients with advanced hepatocellular carcinoma (HCC). Ann Oncol. 2014; 25(Suppl 2):ii14-ii104.

34. Qin S, Bi F, Jin J, et al. Axitinib versus sorafenib as a second-line therapy in Asian patients with metastatic renal cell carcinoma: results from a randomized registrational study. Onco Targets Ther. 2015;8:1363-1373.

35. Escudier B, Eisen T, Stadler WM, et al; TARGET Study Group. Sorafenib in advanced clear-cell renal-cell carcinoma. $N$ Engl J Med. 2007;356(2):125-134.

36. Motzer RJ, Hutson T, Reeves J, et al. Randomized, open-label, phase III trial of pazopanib versus sunitinib in first-line treatment of patients with metastatic renal cell carcinoma (MRCC): results of the COMPARZ trial [abstract]. Ann Oncol. 2012;23(Suppl 9):LBA8_R.

37. Motzer RJ, Hutson TE, Tomczak P, et al. Sunitinib versus interferon alfa in metastatic renal-cell carcinoma. $N$ Engl J Med. 2007;356(2): 115-124.

38. Motzer RJ, Bacik J, Schwartz LH, et al. Prognostic factors for survival in previously treated patients with metastatic renal cell carcinoma. J Clin Oncol. 2004;22(3):454-463. 


\section{Supplementary material}

Table SI List of study centres and corresponding ethics committees or institutional review boards

Center

Ethics committee or institutional review board

City, state/province, postal code, country

Number

1007

1008

1009

1001
Bellberry limited human Research Ethics Committee

Human Research Ethics Committee Research Ethics

and Governance Unit

Tasmania Health \& Medical HREC

IRB Services

Morris A. Blajchman, MD, FRCP(C) (McGill) Physician
129 Glen Osmond Road, Eastwood, SA 5063, Australia

Lower Ground Administration Building, The Prince Charles

Hospital, Rode Road, Chermside, QLD 4032, Australia

HREC Administration UTAS, Private Bag 0I, Hobart, TAS

700I, Australia

372 Hollandview Trail, suite 300, Aurora, Ontario, L4G

0A5, Canada

OncoTargets and Therapy

\section{Publish your work in this journal}

OncoTargets and Therapy is an international, peer-reviewed, open access journal focusing on the pathological basis of all cancers, potential targets for therapy and treatment protocols employed to improve the management of cancer patients. The journal also focuses on the impact of management programs and new therapeutic agents and protocols on
Dovepress

patient perspectives such as quality of life, adherence and satisfaction. The manuscript management system is completely online and includes a very quick and fair peer-review system, which is all easy to use. Visit http://www.dovepress.com/testimonials.php to read real quotes from published authors.

\footnotetext{
Submit your manuscript here: http://www.dovepress.com/oncotargets-and-therapy-journal
} 